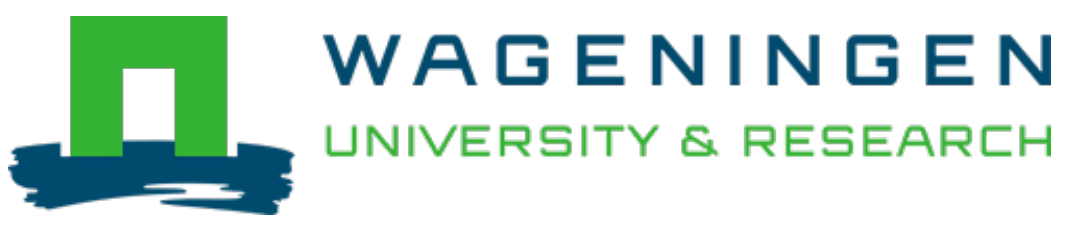

\title{
Temperature control in solid substrate fermentation through discontinuous rotation.
}

\author{
Applied Microbiology and Biotechnology \\ Reu, J.C.; Zwietering, M.H.; Rombouts, F.M.; Nout, M.J.R. \\ https://doi.org/10.1007/bf00170377
}

\begin{abstract}
This publication is made publicly available in the institutional repository of Wageningen University and Research, under the terms of article $25 \mathrm{fa}$ of the Dutch Copyright Act, also known as the Amendment Taverne. This has been done with explicit consent by the author.
\end{abstract}

Article 25 fa states that the author of a short scientific work funded either wholly or partially by Dutch public funds is entitled to make that work publicly available for no consideration following a reasonable period of time after the work was first published, provided that clear reference is made to the source of the first publication of the work.

This publication is distributed under The Association of Universities in the Netherlands (VSNU) 'Article $25 \mathrm{fa}$ implementation' project. In this project research outputs of researchers employed by Dutch Universities that comply with the legal requirements of Article $25 \mathrm{fa}$ of the Dutch Copyright Act are distributed online and free of cost or other barriers in institutional repositories. Research outputs are distributed six months after their first online publication in the original published version and with proper attribution to the source of the original publication.

You are permitted to download and use the publication for personal purposes. All rights remain with the author(s) and / or copyright owner(s) of this work. Any use of the publication or parts of it other than authorised under article $25 \mathrm{fa}$ of the Dutch Copyright act is prohibited. Wageningen University \& Research and the author(s) of this publication shall not be held responsible or liable for any damages resulting from your (re)use of this publication.

For questions regarding the public availability of this publication please contact openscience.library@wur.nl 


\title{
Temperature control in solid substrate fermentation through discontinuous rotation
}

\author{
J. C. de Reu ${ }^{1}$, M. H. Zwietering ${ }^{2}$, F. M. Rombouts ${ }^{3}$, M. J. R. Nout ${ }^{4}$ \\ Department of Food Science, Agricultural University, Bomenweg 2, 6703 HD Wageningen, The Netherlands
}

Received: 20 January 1993/Accepted: 23 April 1993

\begin{abstract}
A laboratory-scale system for controlled dynamic solid substrate fermentation was developed and tested. The fermentation takes place in a stainless steel discontinuously rotating drum reactor, under controlled conditions of temperature, gas composition, relative humidity and direction and rate of rotation. The system was tested on a model fermentation of soya beans with Rhizopus oligosporus. In contrast to the traditional tempe fermentation, a granular product is obtained and build-up of heat and mass gradients is restricted. Despite the discontinuous rotation, the fungal growth continues, as evidenced by the production of heat. The rate of cooling depends on the temperature of the gas flushed through the reactor, the gas flow rate and the length of the rotation period. As a consequence of the homogeneous temperature control, the fungal heat development continued up to $70 \mathrm{~h}$ of fermentation. This is in clear contrast with the traditional tempe fermentation, which is already limited after $36 \mathrm{~h}$ by its own heat accumulation.
\end{abstract}

\section{Introduction}

Tempe is a traditional Indonesian food in which fungi, particularly Rhizopus spp. play an essential role. Yellow-seeded soya beans are the most common and popular raw material (Nout and Rombouts 1990). The equipment required for daily production capacities of 7-1800 kg has been described by Shurtleff and Aoyagi (1980). When scaling up the production by increasing the fermentor size, problems can be expected due to accumulation of metabolic heat [14960 BTU/kg dry solids (1 BTU =1054 J) (Mudgett 1986); $2514 \mathrm{~kJ} / \mathrm{kg}$ of fermented solids (Aidoo et al. 1982)]. Consequently, the temperature within a bed or package of tempe may rise $10-16^{\circ} \mathrm{C}$ above that of the environment. A steep temperature gradient of $3^{\circ} \mathrm{C} / \mathrm{cm}$ bed thickness during

Correspondence to: M. J. R. Nout active growth has been reported in a fermentor employing a bed height of $6.5 \mathrm{~cm}$ (Rathbun and Shuler 1983). The availability of $\mathrm{O}_{2}$ is determined by diffusion, which in turn is determined by porosity, particle size and consistency of the substrate (Alvarez-Martinez 1987; Mitchell et al. 1988). Due to these limitations to mass transfer, $\mathrm{O}_{2}$ levels decreased to approximately $2 \%(\mathrm{v} / \mathrm{v})$ and $\mathrm{CO}_{2}$ increased to $22 \%(\mathrm{v} / \mathrm{v})$. However at $1-6.5 \%(\mathrm{v} / \mathrm{v}) \mathrm{O}_{2}$, rapid fungal growth still occurred (Rathbun and Shuler 1983), implying that the $\mathrm{O}_{2}$ levels measured in tempe would not be growth-limiting.

A change in the reactor configuration can improve the process. Instead of a static packed bed, we developed a rotating drum reactor (RDR). The use of $\mathrm{RDRs}$ has been recently reported for the production of, for example, ethanol (Kargi and Curme 1985; Weiland and Scholz 1990), ochratoxin (Lindenfelser and Ciegler 1975), enzymes (Silman 1980), spores (Larroche and Gros 1986), koji (Mudgett 1986) and for the cultivation of plant cells (Shibasaki et al. 1992).

Some authors consider that the rotation of a fermentation medium would have a negative effect on growth and sporulation (Cannel and Moo-Young 1980; Silman 1980). According to Smith and Aidoo (1988) the main disadvantage of RDRs is that the useful space for fermentation is only approximately $30 \%$ of the total drum volume.

In contrast to research on submerged fermentation, there are no commercial laboratory-scale systems available for solid substrate fermentations. Consequently, we developed a device that can be used for studies on solid substrate fermentations. This paper describes an RDR system with advanced measurement and control features, and illustrates the temperature control in a solid substrate fermentation based on the tempe model.

\section{Materials and methods}

Organism. Rhizopus oligosporus LU 575 NRRL 5905, classified as $R$. microsporus var. oligosporus was grown for 7 days at $30^{\circ} \mathrm{C}$ and maintained on malt extract agar (Oxoid, CM 59). Sporan- 


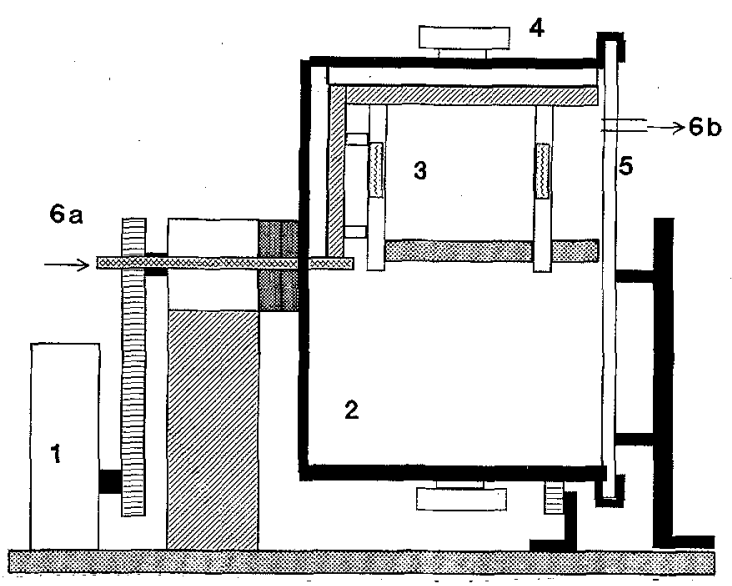

Fig. 1. A cross-sectional view of the rotating drum reactor: 1 , motor; 2, stainless-steel drum; 3 , wiper; 4 , sample port; 5 , static wall with sensors; $6 a / b$, glas in- and outlet, respectively

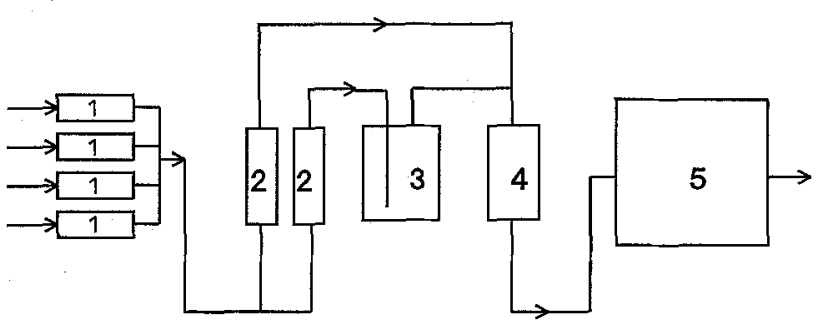

Fig. 2. Schematic view of the gas flow system: 1, mass flow controller valves; 2 , rotameters; 3 , humidifier; 4 , on-line relative humidity measuring unit; 5 , rotating drum reactor

giospore suspensions were obtained by scraping the sporangia off the agar and suspending them into sterile distilled water $+0.1 \%$ $(v / v)$ Tween 80 . The viable count varied between $5 \times 10^{5}$ and $10^{6}$ colony-forming units (cfu) $/ \mathrm{ml}$

Reactor and sensors. Experiments were carried out in a RDR as depicted in Fig. 1. The RDR had an inner diameter of $20 \mathrm{~cm}$ and a length of $15 \mathrm{~cm}$ resulting in a 4.7 volume.

The reactor consisted of two stainless steel main parts, namely the rotating drum itself and the static wall, which includes welded-in sockets for the sensors. Two Pt $100 \Omega$-sensors with a diameter of $3 \mathrm{~mm}$ (Tempcontrol, Voorburg, The Netherlands) were used to measure the temperature, one situated in the substrate and the other in the headspace of the reactor. An autoclavable $\mathrm{O}_{2}$ probe (diameter $25 \mathrm{~mm}$, length $70 \mathrm{~mm}$, Ingold, Urdorf, Switzerland) was placed in the headspace, and was calibrated under process conditions prior to the start of the fermentation. A non-autoclavable probe for relative humidity (I400, Rotronic, Bassersdorf, Switzerland) with a built-in Pt $100 \Omega$-sensor was placed in the headspace after autoclaving. The RDR was used in a temperature-controlled incubator. In order to prevent beans from sticking to the wall, the rotation was supplemented by a sweeping action. This was achieved by a wiper consisting of spring-loaded horizontal and vertical parts. During fermentation, homogeneous samples could be obtained, after rotation, through the sample port.

Gas flow system. Humidified air was provided through the gas inlet tube. The outlet was connected to an $\mathrm{O}_{2}$ and $\mathrm{CO}_{2}$ analyser (Uras 3, Hartmann and Braun, Frankfurt-am-Main, Germany). The relative humidity of the ingoing gas was controlled by mixing a water-saturated flow and a dry gas flow. The relative humidity was measured in the gas stream before the gas inlet. The gas composition could be controlled using four mass flow controllers $(10$, 100,1000 and $2000 \mathrm{sccm}$, Type 1259B, MKS Instruments, München, Germany) and one multi-gas controller (147, MKS Instruments, München, Germany) (Fig. 2). Gas of desired composition could be produced by mixing $\mathrm{O}_{2}, \mathrm{CO}_{2}, \mathrm{~N}_{2}$ and air, with flow rates varying from 0 to $3 \mathrm{l} / \mathrm{min}$ and relative humidity levels ranging from 50 to $100 \%$.

Measurement and control system. All sensors were linked to a computer-controlled measurement and control system consisting of hardware formed by a distributed controller ( $\mu$ DCS 6000 , Analog Devices, Oosterhout, The Netherlands), controller software (FIXDMACS 1.3, Intellution, Norwood, Mass., USA) and a personal computer (Vectra QS/16S with 80387 co-processor, Hewlett Packard, Grenoble, France). The rotation speed (0-30 rpm), direction (forward/reverse) and duration could be programmed and controlled by FIXDMACS programming blocks, but manual intervention was also possible. The process data were stored on a hard disc prior to analysis (plotting, ASCII transfer to Lotus, etc.).

Fermentation process. Yellow-seeded soya beans (Glycine max) were dehulled by dry abrasion and soaked overnight with accelerated acidification (Nout et al. 1987). Subsequently the beans ( $\mathrm{pH}$ soak water $<4.2$ ) were washed with tap water and boiled for $20 \mathrm{~min}$, cooled and superficially dried (15-30 min, at room temperature). The RDR was autoclaved for $20 \mathrm{~min}$ at $121^{\circ} \mathrm{C}$, before filling it with inoculated soya beans $(1 \mathrm{~kg} / \mathrm{run})$. After inoculation, beans were transferred to the previously autoclaved and cooled RDR.

\section{Results and discussion}

\section{Effect of aeration}

One way of preventing high substrate temperatures is to use forced evaporation to absorb the metabolic heat generated. The degree of evaporation may be controlled by the flow rate and the relative humidity $(\mathrm{RH})$ of the gas (Barstow et al. 1988). According to Ryoo et al. (1991) mixing dry and wet gas achieves better control of evaporation than increasing the gas flow rate. In addition to heat removal, gas flow may serve to control the composition of the atmosphere in the reactor. Initially we used compressed air as the aeration gas since it is cheapest. To simulate the situation in a traditional static fermentation we tested the effect of air flow in the substrate temperature in the RDR at stand-still. Different flow rates $(0,0.25,0.5,0.75,1,1.5$ and $21 /$ min) with moisturized air (RH 95\%) were used. The substrate temperature showed a similar pattern as the growth curve for fungal biomass including a lag phase, an exponential phase and a stationary or autolytic phase with concomitant temperature decrease.

In Fig. 3 the substrate temperature during a static fermentation with an air flow rate of $1 \mathrm{l} / \mathrm{min}$ is presented. Table 1 summarizes results with air flow rates ranging from 0.25 to $2.00 \mathrm{l} / \mathrm{min}$. This table shows that flow rates $<0.75 \mathrm{l} / \mathrm{min}$ were limiting to the metabolic activity. The highest temperatures were reached with air flow rates of between 0.75 and $1.51 / \mathrm{min}$. Due to heat removal the temperature of the gas increased by $3-4^{\circ} \mathrm{C}$. 


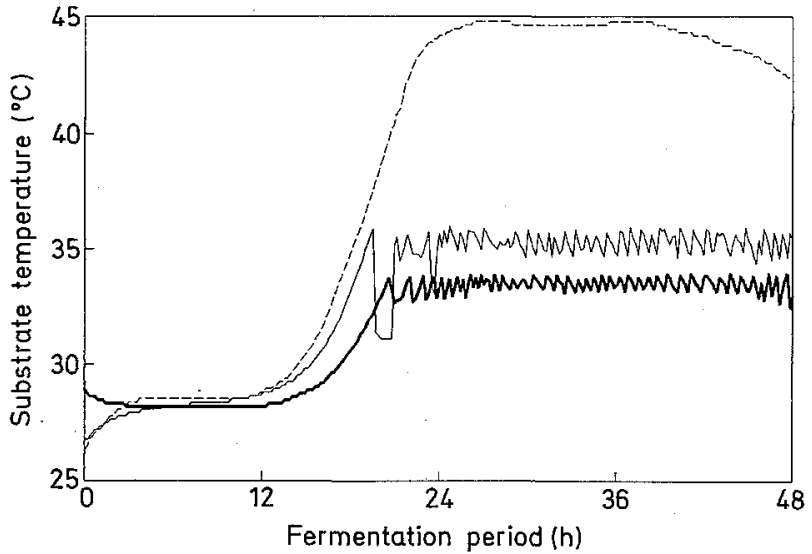

Fig. 3. Development of substrate temperature in the rotating drum reactor during static and discontinuously rotated fermentations with air gas flow of $29^{\circ} \mathrm{C}, 95 \%$ relative humidity at $1 \mathrm{l} / \mathrm{min}$ and surrounding temperature of $30^{\circ} \mathrm{C}$ : - , discontinuously rotated, rotation temperature $\left(T_{\mathrm{R}}\right)=34^{\circ} \mathrm{C}$ and rotation period $\left(t_{\mathrm{r}}\right)=1 \mathrm{~min} ;-\ldots$, static; - - , discontinuously rotated, rotation temperature $\left(T_{\mathrm{R}}\right)=36^{\circ} \mathrm{C}$ and rotation period $\left(t_{\mathrm{r}}\right)=1 \mathrm{~min}$

Flow rates exceeding $1.5 \mathrm{l} / \mathrm{min}$ resulted in lower temperatures due to increased heat removal.

\section{Effect of rotation temperature and rotation period}

The aim of rotation was to minimize heat and mass transfer limitations and to create a homogeneous product by breaking the tempe mass into smaller particles. Several authors reported that rotation of fermentation media would have a negative effect on growth and sporulation (Cannel and Moo-Young 1980; Silman 1980). One of our aims was to investigate whether growth inhibition would occur as result of discontinuous rotations. An advantage of discontinuous over continuous rotation would be that less energy is required for rotation and that the fungal mycelium would be exposed to a minimum of shear. In principle, a compromise between maximum growth (minimum rotation) and minimum temperature gradients (maximum rotation) would be required.

Table 1. Influence of air flow on the temperature of substrate and gas in the reactor during a static fermentation in the rotating drum reactor

\begin{tabular}{|c|c|c|c|}
\hline $\begin{array}{l}\text { Flow rate } \\
(1 / \mathrm{min})^{\mathrm{b}}\end{array}$ & $\begin{array}{l}\mathrm{T}_{\max } \\
\text { substrate } \\
\left({ }^{\circ} \mathrm{C}\right)\end{array}$ & $\begin{array}{l}\mathrm{T}_{\max } \\
\text { gas } \\
\left({ }^{\circ} \mathrm{C}\right)\end{array}$ & $\begin{array}{l}\text { Temperature } \\
\text { slope }^{\text {a }} \\
\left({ }^{\circ} \mathrm{C} / \mathrm{h}\right)\end{array}$ \\
\hline 0.25 & 29.41 & 28.98 & 0.22 \\
\hline 0.50 & 39.26 & 32.41 & 1.06 \\
\hline 0.75 & 45.56 & 34.91 & 2.21 \\
\hline 1.00 & 44.61 & 34.34 & 1.81 \\
\hline 1.50 & 45.41 & 33.74 & 1.76 \\
\hline 2.00 & 40.75 & 33.69 & 1.53 \\
\hline
\end{tabular}

${ }^{a}$ Maximum rate of temperature increase during the active growth phase

${ }^{\mathrm{b}}$ Relative humidity of air flow $=95 \%$; surrounding temperature

$=30^{\circ} \mathrm{C}$; temperature of gas at inlet $=29^{\circ} \mathrm{C}$

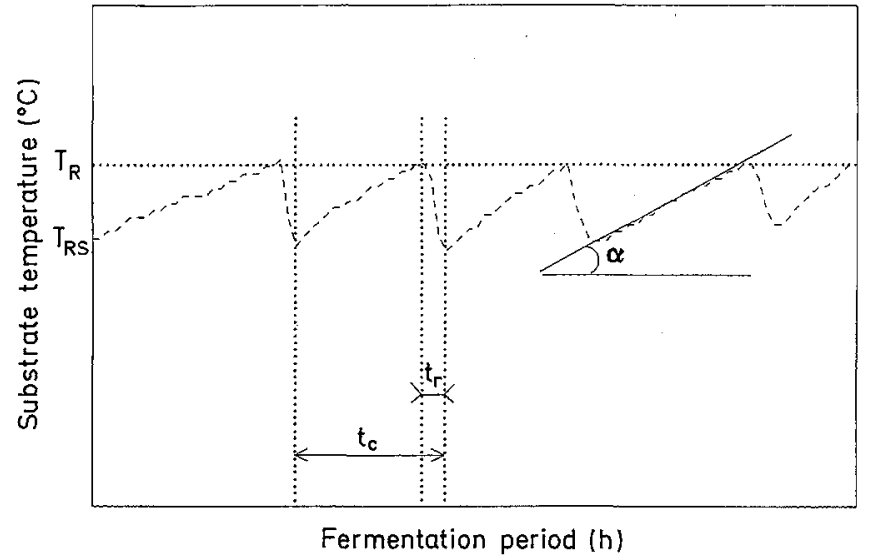

Fig. 4. Detailed view of the temperature pattern during discontinuously rotated fermentation: $T_{\mathrm{r}}$, rotation temperature $\left({ }^{\circ} \mathrm{C}\right) ; T_{\mathrm{RS}}$, temperature at end of rotation period $\left({ }^{\circ} \mathrm{C}\right) ; t_{\mathrm{c}}$, cycle period $(\mathrm{h}) ; t_{\mathrm{r}}$, rotation period $(\mathrm{h}) ; \alpha$, slope $\frac{T_{\mathrm{r}}-T_{\mathrm{RS}}}{t_{\mathrm{c}}-t_{\mathrm{r}}}$

One may programme the discontinuous rotation according to a pre-defined timescale. However, due to variations in the lag phase, the actual start of the active growth is difficult to predict. Consequently, we chose to couple the rotation programme directly to the actual fungal metabolic activity as indicated by the substrate temperature.

Due to the mixing with gas of a lower temperature, the substrate temperature is reduced to $T_{\mathrm{RS}}$ (Fig. 4) at the end of rotation. During subsequent stand-still the substrate temperature increases again to $T_{\mathrm{R}}$. The rate of temperature rise could be expressed as slope $\alpha$ (Fig. 4).

To achieve adequate size reduction of the block formed, rotation into both reverse and forward directions was required. A rotation scheme in which the rotation temperature $\left(T_{\mathrm{R}}\right)$, rotation rate $(\mathrm{rpm})$, rotation direction and rotation period $\left(t_{\mathrm{r}}\right)$ were defined in a programme block of the FIXDMACS programme is shown in Table 2. There was no rotation during the lag

Table 2. Rotation scheme as defined in a programme block of FIXDMACS for an experiment with a rotation temperature $\left(T_{\mathrm{R}}\right)$ of $34^{\circ} \mathrm{C}$ and rotation period $\left(t_{\mathrm{r}}\right)$ of $1 \mathrm{~min}$

\begin{tabular}{lllc}
\hline Step Event & $\begin{array}{l}\text { Rotation rate } \\
(\mathrm{rpm})\end{array}$ & $\begin{array}{l}\text { Rotation time } \\
(\mathrm{s})\end{array}$ \\
\hline 1 & If $T_{\text {sub }}>34^{\circ} \mathrm{C}$ GOTO step 3 & 0 & 0 \\
2 & GOTO step 1 & 0 & 0 \\
3 & Rotate forwards & 6 & 7 \\
4 & Rotate backwards & 4 & 7 \\
5 & Rotate forwards & 6 & 7 \\
6 & Rotate backwards & 4 & 7 \\
7 & Rotate forwards & 6 & 32 \\
8 & GOTO step 1 & 0 & 0 \\
& & & Total: 60
\end{tabular}

$T_{\text {sub }}=$ substrate temperature 
Table 3. Temperature control during discontinuous rotated fermentation in a rotating drum reactor flushed with air of $29^{\circ} \mathrm{C}$, $95^{\circ} \mathrm{C}$ relative humidity, at $1 \mathrm{l} / \mathrm{min}$ for different rotation temperatures and rotation periods

\begin{tabular}{|c|c|c|c|c|}
\hline $\begin{array}{l}\text { Rotation } \\
\text { temperature } \\
T_{\mathrm{R}} \\
\left({ }^{\circ} \mathrm{C}\right)\end{array}$ & $\begin{array}{l}\text { Rotation } \\
\text { period } \\
t_{\mathrm{r}} \\
(\min )\end{array}$ & $\begin{array}{l}\text { Temperature } \\
\text { drop } \\
T_{\mathrm{R}}-T_{\mathrm{RS}} \\
\left({ }^{\circ} \mathrm{C}\right)\end{array}$ & $\begin{array}{l}\text { Cycle } \\
\text { time } \\
t_{\mathrm{c}} \\
\text { (min) }\end{array}$ & $\begin{array}{l}\text { Average } \\
\text { Slope } \alpha \\
\left(T_{\mathrm{R}}-T_{\mathrm{RS}}\right) /\left(t_{\mathrm{c}}-t_{\mathrm{r}}\right) \\
\left({ }^{\circ} \mathrm{C} / \mathrm{h}\right)\end{array}$ \\
\hline 32 & 1 & $0.36 \pm 0.12$ & $9 \pm 7$ & 2.8 \\
\hline 32 & 5 & $0.30 \pm 0.11$ & $16 \pm 9$ & 1.4 \\
\hline 34 & 1 & $0.92 \pm 0.22$ & $39 \pm 11$ & 1.5 \\
\hline 34 & 5 & $2.09 \pm 0.80$ & $83 \pm 65$ & 1.2 \\
\hline 36 & 1 & $1.17 \pm 0.41$ & $40 \pm 13$ & 1.8 \\
\hline 36 & 5 & $2.31 \pm 0.42$ & $73 \pm 36$ & 1.9 \\
\hline 38.5 & 1 & $2.91 \pm 0.46$ & $39 \pm 11$ & 5.8 \\
\hline 38.5 & 5 & $3.69 \pm 0.58$ & $142 \pm 81$ & 2.3 \\
\hline 41 & 1 & $3.03 \pm 0.43$ & $36 \pm 15$ & 5.7 \\
\hline
\end{tabular}

Surrounding temperature $=30^{\circ} \mathrm{C}$

phase. As a result of spore germination and growth, the substrate temperature was allowed to increase until the defined rotation substrate temperature $\left(T_{R}\right)$ was reached (Fig. 4).

Table 3 summarizes the temperature fluctuations obtained at rotation temperatures ranging from $32^{\circ} \mathrm{C}$ to $41^{\circ} \mathrm{C}$ and rotation periods of 1 and $5 \mathrm{~min}$. Air of $95 \%$ relative humidity and $30^{\circ} \mathrm{C}$ was put through at 1 $1 / \mathrm{min}$. With increasing rotation temperature and rotation periods, the temperature difference $T_{R}-T_{R S}$ increased. This was due to the similarly increasing difference between $T_{\mathrm{R}}$ and $T_{\text {gas }}$, and the increased exposure to the gas, respectively. An increase of $t_{\mathrm{r}}$ from 1 to 5 min resulted in almost all cases, except at $T_{\mathrm{R}} 36^{\circ} \mathrm{C}$, in a decrease of $\alpha$. This effect may have been caused by increasing damage of mycelium by longer rotation. In addition, the stronger cooling effect of prolonged rotation could also influence $\alpha$. We did not investigate the pure effect of prolonged rotation on mycelium disruption. However this could be done by ensuring a constant difference between the temperature of the in-going gas and the substrate temperature in order to avoid the effect of cooling at increased $t_{\mathrm{r}}$.

In Fig. 3 the temperature curves at $\mathrm{T}_{R}=34^{\circ} \mathrm{C}$ and $\mathrm{T}_{\mathrm{R}}=36^{\circ} \mathrm{C}$ both with $t_{\mathrm{r}}=1 \mathrm{~min}$ are illustrated together with the temperature curve of a static fermentation in the same reactor at the same air flow $\left(11 / \mathrm{min}, 30^{\circ} \mathrm{C}\right.$, 95\% RH).

In the traditional static tempe process, the substrate temperature regulates the growth of the mould. Figure 3 shows that at a maximum substrate temperature of $44^{\circ} \mathrm{C}$, growth was strongly inhibited and the accumulated heat was dissipated slowly, resulting in a decrease of the substrate temperature beyond $36 \mathrm{~h}$ of incubation. In the RDR the slope $(\alpha)$ increased gradually to a constant level and could be maintained until the chemical composition of the substrate became inhibitory, probably by substrate limitation. The slope $\alpha$ increased with higher rotation temperatures $\left(T_{\mathrm{R}}\right)$; whereas the maximum slope during the static process was $1.8^{\circ} \mathrm{C} / \mathrm{h}$ (Table $1,1 \mathrm{l} / \mathrm{min}$ ), the slope $\alpha$ in the dynamic process was maximum $\left(5.8^{\circ} \mathrm{C} / \mathrm{h}\right)$ at $T_{\mathrm{R}}=38.5^{\circ} \mathrm{C}$. The increase of the temperature slope $(\alpha)$ resulted from two effects, namely firstly the production of metabolic heat, which we assume to be maximal at the optimal growth temperature (approx. $37^{\circ} \mathrm{C}$ ), and secondly the levelling of a temperature gradient within the beans, which was created by the cooling effect during rotation. As a consequence of the homogeneous temperature control, the fungal heat development continued for up to $70 \mathrm{~h}$ of fermentation. This is in clear contrast to the traditional tempe fermentation, which was limited already after $36 \mathrm{~h}$ by its own heat accumulation.

The avoidance of uncontrolled and stormy heat accumulation with consequent excessive and limiting temperatures opens interesting prospects for increasing the efficiency of substrate modification in fungal solid substrate fermentations.

Compared with rotating drum systems described elsewhere (Silman 1980; Kargi and Curme 1985; Lindenfelser and Ciegler 1975; Shibasaki et al. 1992), which operate under fixed conditions for temperature, rotation speed and air flow rate and which do not have options for data logging or computer control, the present system has a number of advantages. In addition to measurement and control of multiple parameters, the set values and actions can be activated by the process itself, e.g. temperature activated rotation as in Table 2. The optimization of tempe processes requires investigation of the kinitics of substrate modification under defined and controlled conditions. This is presently being studied.

Acknowledgement. We gratefully acknowledge the financial support of Nutricia Research Zoetermeer, The Netherlands.

\section{References}

Aidoo KE, Hendry R, Wood BJB (1982) Solid substrate fermentations. Ad Appl Microbiol 28:201-237

Alvarez-Martinez LR (1987) Modelling fungal Rhizopus oligosporus growth on extruded corn by solid substrate fermentation. Ph. D. Thesis, Colorado State University, Dissertation Abstracts International B49, 1284

Barstow LM, Dale BE, Tengerdy RP (1988) Evaporative temperature and moisture control in solid substrate fermentation. Biotechnol Tech 2:237-242

Cannel E, Moo-Young M (1980) Solid-state fermentation systems. Process Biochem 15:2-7, 24-28

Kargi F, Curme JA (1985) Solid state fermentations of sweet sorghum to ethanol in a rotary-drum fermentor. Biotechnol Bioeng 17:1122-1125

Larroche C, Gros J-B (1986) Spore production of Penicillium roquefortii in fermentors filled with buckwheat seeds: batch and semi-continuous cultivation. Appl Microbiol Biotechnol 24:134-139

Lindenfelser LA, Ciegler A (1975) Solid substrate fermentor for ochratoxin A production. Appl Microbiol 29:323-327

Mitchell DA, Doelle HW, Greenfield PH (1988) Improvement of growth of Rhizopus oligosporus on a model solid substrate. Biotechnol Lett 10:497-502

Mudgett RE (1986) Solid-state fermentations. In: Demain AL, Solomon NA (eds) Manual of industrial microbiology and biotechnology. American Society for Microbiology, Washington, D. C. pp 66-83 
Nout MJR, Rombouts FM (1990) Recent developments in tempe research. J Appl Bacteriol 69:609-633

Nout MJR, Dreu MA de, Zuurbier AM, Bonants-van Laarhoven TMG (1987) Ecology of controlled soya bean acidification for tempe manufacture. Food Microbiol 4:165-172

Rathbun BL, Shuler ML (1983) Heat and mass transfer effects in static solid substrate fermentation: design of fermentation chambers. Biotechnol Bioeng 25:929-938

Ryoo D, Murphy VG, Karim MN, Tengerdy RP (1991) Evaporative temperature and moisture control in a rocking reactor for solid substrate fermentation. Biotechnol Tech 5:19-24

Shibasaki N, Hirose K, Yonemoto T, Tadaki T (1992) Suspension culture of Nicotiana tabacum cells in a rotary drum bioreactor. J Chem Technol Biotechnol 53:359-363

Shurtleff W, Aoyagi A (1980) The book of tempeh, volume II: tempe production. New-Age Foods, Lafayette, California

Silman RW (1980) Enzyme formation during solid-substrate fermentation in rotating vessels. Biotechnol Bioeng 22:411-420

Smith JE, Aidoo KE (1988) Growth of fungi on solid substrates. In: Berry DR (ed) Physilogy of industrial fungi. Blackwell Scientific Publications, Oxford, pp 249-269

Weiland P, Scholz CH (1990) Ethanol fermentation in a solidphase process. Dechema Biotechnology Conferences 4 . VCH Verlagsgesellschaft, Weinheim, pp 855-858 